\title{
ESTUDO DO PROCESSO DE RECICLOS EM BATELADA UTILIZANDO DIFERENTES COMPOSTOS ORGÂNICOS DA LIPASE B DE Candida antarctica IMOBILIZADA EM ESPUMA FLEXÍVEL DE PU DE DESIDADE 30 E18
}

\author{
ANTUNES, A. ${ }^{1}$, FICANHA, A. M. M. ${ }^{1}$, NYARI, N.L.D. ${ }^{1}$, ZAMADEI, R. ${ }^{1}$, M. BOPSIN ${ }^{1}$, K. L. \\ LEVANDOSKI $^{1}$, A. R. PAULAZZI ${ }^{1}$, ZENI, J. ${ }^{1}$, DALLAGO, R.M. ${ }^{1}$ \\ ${ }^{1}$ Universidade Regional Integrada do Alto Uruguai e das Missões - Campus de Erechim, \\ Departamento de Engenharia de Alimentos, Erechim, Rio Grande do Sul, Brasil \\ nenaantunes@gmail.com
}

\begin{abstract}
RESUMO - Enzimas são biocatalisadores com ampla aplicação em diversos tipos de reações, porém, o custo elevado das enzimas solúveis é um dos limitadores de sua aplicação, pois são descartadas após a reação e seu uso se torna economicamente inviável. O objetivo deste trabalho foi avaliar a estabilidade operacional da enzima lipase de Candida antarctica B (CALB) imobiliza em poliuretano flexível de densidades 30 e 18 . O processo de imobilização se deu com a mistura de uma solução enzimática mais, monômeros, surfactantes, extensores de cadeia e água. Devido à falta de uma metodologia definida na literatura, a estabilidade operacional do reuso foi realizada por lavagens com diferentes solventes orgânicos (hexano, metanol, etanol e solução padrão) com reciclos de reuso de 24 horas. Os resultados demonstram a possibilidade de reuso dos derivados, sendo que para todos os solventes utilizados o número de reciclos foi de $15 \mathrm{com}$ atividade residual superior a 50\%, tanto para o derivado de densidade 30 quanto para o de densidade 18.
\end{abstract}

\section{INTRODUÇÃO}

A enzima lipase de Candida antarctica tipo B (CALB) é um excelente catalisador para vários tipos de reações, dentre elas, a esterificação. Um dos principais problemas em utilizar enzimas livres em meios orgânicos é por serem solúveis, flexíveis, com estrutura catalítica ordenada, delicada e frágil. Para isso e necessário utilizá-la na forma imobilizada, pois aumentam o número de moléculas por unidade de área e, consequentemente há um aumento das propriedades cinéticas e da eficiência das reações (Dalla-Vecchia et al., 2004; Ozyilmaz e Gezer, 2010). Neste sentido, o uso de técnicas que possibilitem à estabilidade operacional é desejável na produção de biocatalisadores para aplicações industriais, tais como, a imobilização de enzimas.

Desta forma, observa-se um crescente aumento na utilização da técnica de imobilização de enzimas dentro do campo da biotecnologia aplicada. As enzimas imobilizadas aumentam o número de moléculas por unidade de área e, consequentemente, a eficiência da reação. Além disso, as vantagens incluem também a reutilização da enzima, permitindo o seu uso contínuo; o aumento das propriedades cinéticas que melhora o controle do processo catalítico; e o aumento da estabilidade (Dalla-Vecchia et al., 2004). 
Nesse contexto, o objetivo deste trabalho foi testar o reuso da enzima lipase comercial de Candida antarctica B imobilizada em situ em espuma flexível de PU em diferentes densidades, na síntese de oleato de etila.

\section{MATÉRIAS E MÉTODOS}

A enzima utilizada foi a lipase de Candida antarctica B (Novozyme NZL-102-LYOHQ) e as proporções dos monômeros, surfactantes, extensores de cadeia e água para as diferentes densidade de estudos foram cedidas pela Tasca Estofados e Cia (empresa fabricante de espuma flexíveis de poliuretano). Para o imobilizado D30 utilizou-se as proporções dos monômeros $(68,85 \%)$, surfactantes $(0,6 \%)$, extensores de cadeia $(28,47 \%)$ e água $(1,95 \%)$, para o imobilizado D20 as proporções dos monômeros foram $(57,35 \%)$, surfactantes $(0,76 \%)$, extensores de cadeia $(37,55 \%)$ e água $(2,86 \%)$ e para o imobilizado D18 as proporções dos monômeros $(58,71 \%)$, surfactantes $(0,98 \%)$, extensores de cadeia $(37,98 \%)$ e água $(2,35 \%)$ (Figura 11), para as porcentagens dos componentes do PU deve-se levar em consideração a volatilidade dos mesmo. Os solventes utilizados foram hexano (Quimex 97\% de pureza), metanol (Quimex 97\% de pureza) e etanol (Quimex 97\% de pureza).

\subsection{Imobilização}

O procedimento experimental para imobilização da Candida antarctica B (CALB) em espuma flexível de PU se deu com o emprego da enzima em estado líquido, com preparo de solução enzimática ( $2 \mathrm{~g}$ em $20 \mathrm{~mL}$ de água destilada). O imobilizado foi produzido pela mistura da enzima em solução (correspondendo a $10 \%$ do volume total dos monômeros). $\mathrm{O}$ processo de preparo para imobilização da CALB em espuma flexível de PU inicia com a mistura dos monômeros (poliol e copolímero) em um béquer, os quais são homogeneizados por 15 segundos. Em seguida é adicionada a essa mistura a solução enzimática a qual também se faz a homogeneização. Após é incorporado a mistura do béquer, a ASA (amina, silicone e água), em concomitante é feita a adição do estanho, e por fim é vertido ao béquer o isocianato o qual dá o início do processo de polimerização. A mistura de todos os compostos que fazem parte do PU é vertida para um recipiente retangular de alumínio (recipiente que dará forma ao polímero) previamente untada com vaselina sólida. Para ambas as densidades o procedimento de imobilização foi o mesmo.

Após aproximadamente 1 minuto ocorreu a expansão da espuma e a completa polimerização da mesma, possibilitando visualizar algumas características da espuma formada, como conformação, flexibilidade, maciez, firmeza, porosidade interna e resistência (Lucas et al., 2001; Santos, 2011). Cabe ressaltar que o método de imobilização utilizado nesta pesquisa consiste no método de encapsulamento, onde ocorre a formação de uma estrutura porosa na presença da enzima, envolvendo-a em uma estrutura tridimensional, realizando o "confinamento" da proteína no polímero insolúvel, resultando no biocatalisador imobilizado (Dalla-Vecchia et al., 2004; Gonçalves, 2007).

\subsection{Atividade Enzimática- Esterificação}

A atividade de esterificação foi realizada pela quantificação da reação de síntese do ácido oleico e etanol (razão molar $1: 1(\mathrm{v} / \mathrm{v})$ ). A reação foi conduzida a $40{ }^{\circ} \mathrm{C}, 160 \mathrm{rpm}$ por 40 min. Esta foi iniciada pela adição da enzima $(0,1 \mathrm{~g})$ ao meio reacional, em frascos de vidro 
com tampa, mantidos em agitador orbital. Alíquotas de $500 \mu \mathrm{L}$ foram retiradas do meio reacional em triplicata no início da reação. A cada amostra foram adicionados $15 \mathrm{~mL}$ de uma solução de acetona-etanol (1:1) (v/v) para paralisar a reação e para extração de éster de oleato de etila segundo Paroul et al. (2010 e 2011). A quantidade de ácido consumida foi determinada por titulação com $\mathrm{NaOH} 0,05 \mathrm{M}$ até $\mathrm{pH}$ 11. Uma unidade de atividade enzimática foi definida como a quantidade de enzima que consome $1 \mu \mathrm{mol}$ de ácido graxo por minuto, nas condições do ensaio. A atividade enzimática foi calculada baseando em Brígida et al., 2010).

\subsection{Determinação do Rendimento}

O rendimento do imobilizado foi calculado pela porcentagem da razão da atividade total da enzima livre em solução utilizado na imobilização e da atividade total do imobilizado (o qual considera a massa total de imobilizado produzido (Brígida et al., 2010).

\subsection{Estabilidade operacional}

A estabilidade operacional foi realizada em batelada de 24 horas, tanto para espuma de densidade 30 como para a de densidade 18. Este procedimento foi realizado no final de cada ciclo de reação, no qual, o produto (fase líquida) foi removido com uma pipeta e foi mantida a fase sólida (derivado imobilizado). As reações foram repetidas até o derivado chegar a uma atividade de esterificação residual maior ou igual a $50 \%$ da atividade inicial.

Depois de transcorrido o tempo das reações de síntese (40 minutos de reação), o meio reacional foi removido de cada um dos sistemas, após a remoção do meio reacional, o derivado imobilizado foi submetido a uma etapa de lavagem com os diferentes solventes, sendo eles, hexano, metanol, etanol ( $1 \mathrm{vez}$ com $5 \mathrm{~mL}$ de cada um dos solventes), o mesmo procedimento foi avaliado para a solução padrão de síntese (ácido oleico:etanol). Após, o meio foi centrifugado a $5000 \mathrm{rpm}$. Retiram-se os solventes sobrenadantes, deixou-se o derivado em estufa a $40{ }^{\circ} \mathrm{C}$ por aproximadamente 24 horas para a evaporação do solvente residual, com exceção ao frasco reacional do imobilizado da solução padrão. Posteriormente, as mesmas quantidades de solução padrão foram adicionadas ao derivado para a próxima reação.

\section{RESULTADOS E DISCUSSÕES}

A reutilização de enzimas em mais de um ciclo de reação é um dos principais objetivos da imobilização, este fato é importante para as enzimas lipase devido ao seu preço, visto que, o custo da enzima é um dos principais problemas quando se refere a sua aplicação industrial. A possibilidade de reutilizar a lipase CALB imobilizada foi determinada por reações de síntese de oleato de etila, apresentados nas Figuras 1 e 2 respectivamente.

Figura 1 - Número de reciclos da lipase imobilizada em PU de densidade 30 com lavagens em diferentes solventes 

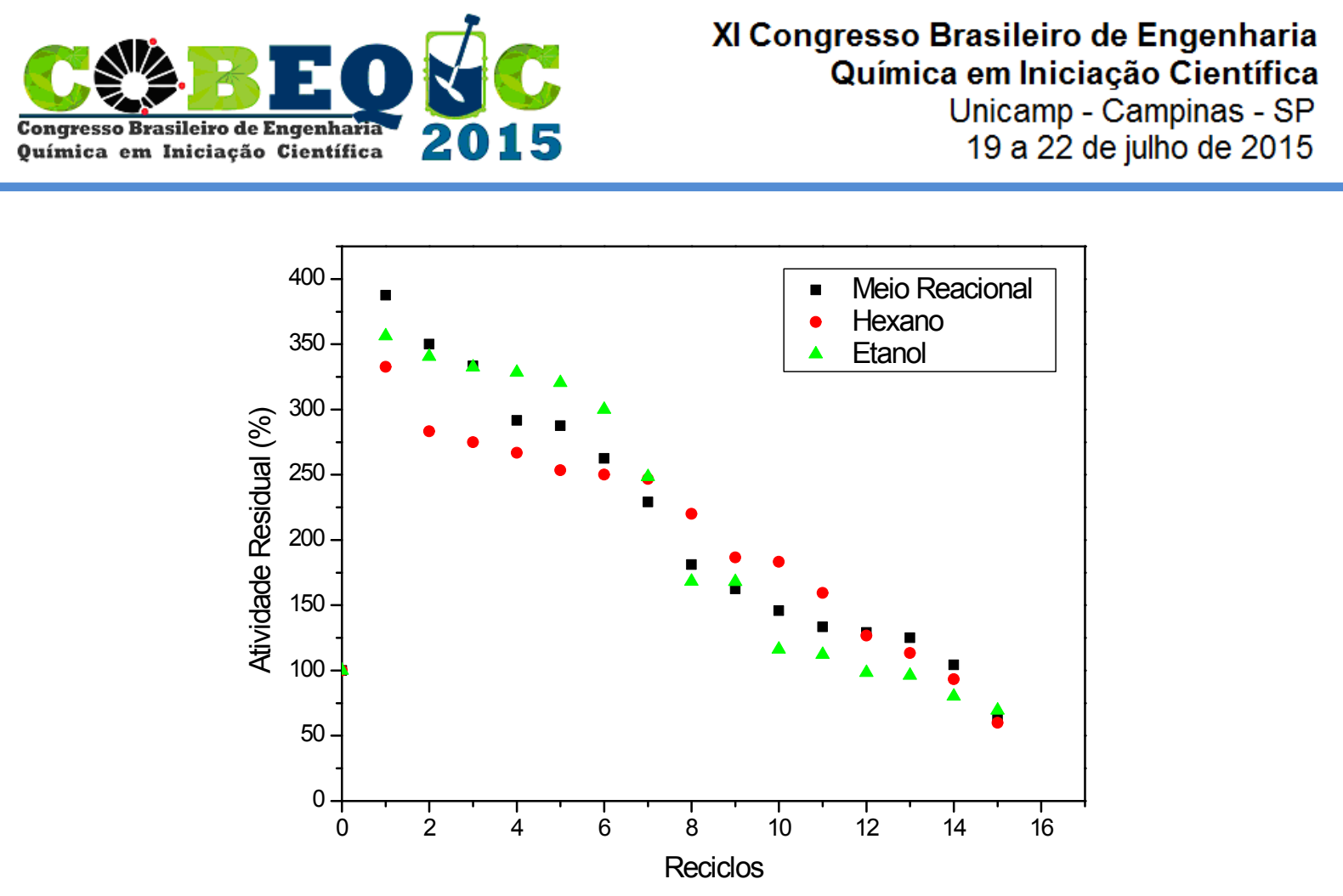

Considerou-se para o reciclo, atividade residual maior ou igual a $50 \%$ do valor da atividade inicial 1. Na Figura 1 (poliuretano densidade 30), os 3 solventes, hexano, etanol e solução padrão apresentaram um número de reuso igual a 15 quando o imobilizado atingiu a porcentagem de critério de avaliação, e optou-se por parar o processo de reciclos devido a perda considerável de massa do imobilizado. O metanol não foi eficiente no processo de secagem, pois, após 24 horas em estufa ainda observa-se solvente no frasco de reação, e por não saber qual seria a influencia do solvente na atividade de esterificação, optou-se por não utiliza-lo nesse estudo.

No decorrer do estudo dos reciclos com lavagem, verificou-se perda de massa significativa dos imobilizados, portanto, optou-se por parar esse estudo quando os mesmo atingiram 15 ciclos, fazendo com que a atividade residual caísse bruscamente.

Figura 2 - Número de reciclos da lipase imobilizada em PU de densidade 18 com lavagens em diferentes solventes 

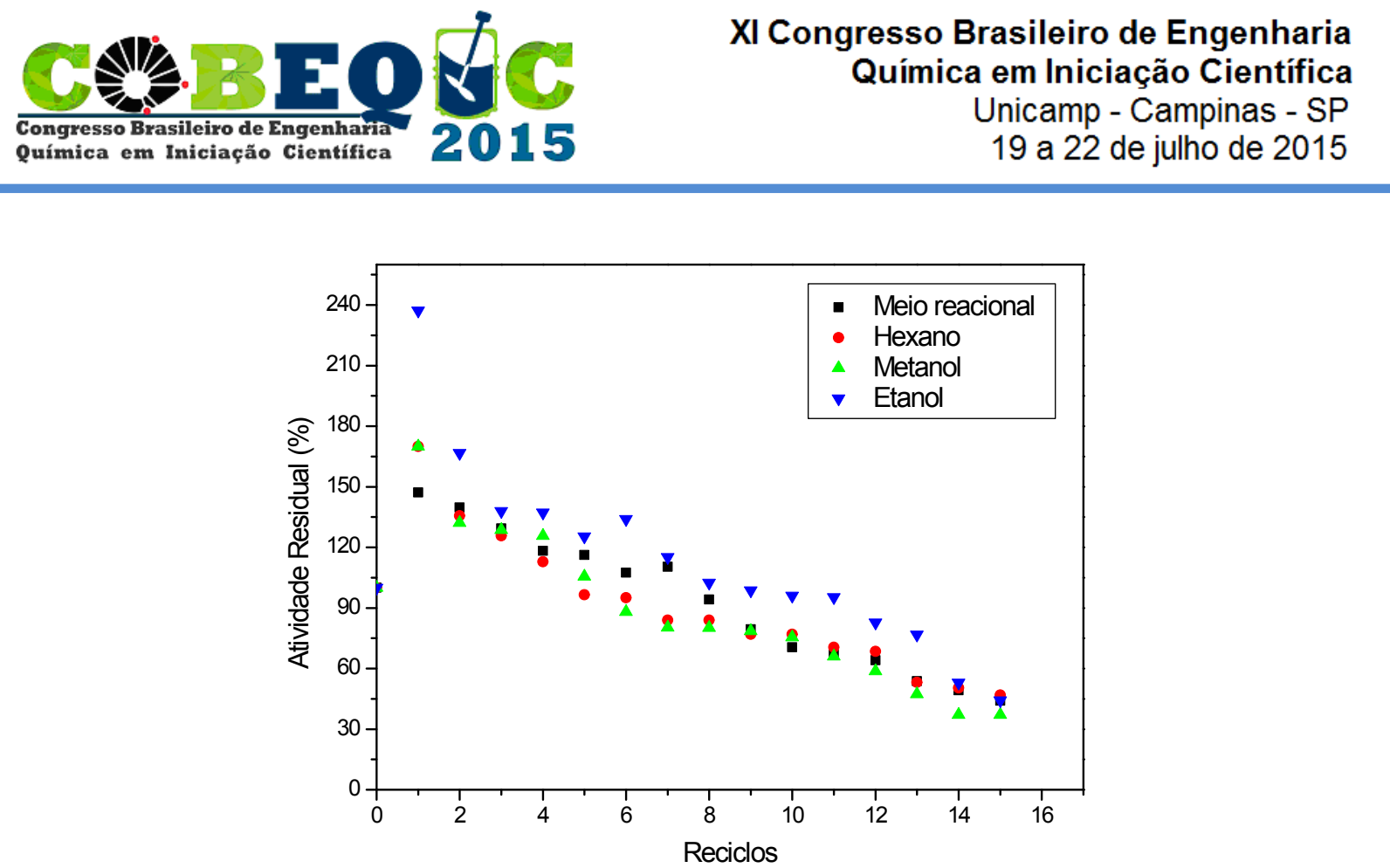

A Figura 2 (poliuretano densidade 18) apresenta a mesma tendência observada para todos os solventes, dos quais um é o próprio meio reacional, sugere-se então, não ser o processo de lavagem o fator determinante para o aumento da atividade residual após o primeiro ciclo, mas sim o período de tempo entre ciclos e a secagem do suporte o que poderia estar influenciando nesse processo. Estes resultados podem ser considerados bons, pois a enzima imobilizada poderá ser utilizada em ciclo batelada por várias vezes, o que para a indústria se torna vantajoso, em relação ao custo da utilização de enzimas imobilizadas. Cabe ressaltar que o suporte onde a enzima está imobilizada não degrada, quando utilizado em reações com solventes orgânicos.

A seleção do solvente orgânico é um fator importante na catálise enzimática em meio não aquoso, devido à interferência direta do solvente na atividade, estabilidade e especificidade da enzima. Os solventes menos nocivos às enzimas são os mais hidrofóbicos, por não interagirem significativamente com a água necessária à enzima. As enzimas, quando em suspensão em solventes hidrofóbicos, requerem substancialmente uma menor quantidade de água para manutenção de sua atividade em comparação às enzimas suspensas em solventes hidrofílicos (Martins, 2012; Martins et al., 2014).

\section{CONCLUSÕES}

Os resultados obtidos no presente trabalho são bastante satisfatórios, pois a CALB imobilizada em poliuretano de diferentes densidades (30 e 18) pode ser utilizada por até 15 reciclos de reuso batelada, em meio reacional com presença de solventes orgânicos (hexano, metanol, etanol e solução padrão), sem que o suporte seja degradado.

\section{REFERÊNCIAS}

BITENCOURT, C. C.; PEREIRA, E. B. Síntese de ésteres formadores de aromas empregando lipases imobilizadas em quitosana por adsorção física. Rev. Inic. Cientif., v. 4, 2009. 
BRÍGIDA, A. I. S.; CALADO, V. M. A.; GONÇALVES, L. R. B.; COELHO, M. A. Z. Effect of chemical treatments on properties of green coconut fiber. Carbohydr. Polym, v. 79, p. 832-838, 2010.

DALLA VECCHIA, C.; BOWER, R. G.; THEUNS, T.; BALOGH, M. L.; MAZZOTTA, P., FRENK, C. S. Quenching cluster cooling flows with recurrent hot plasma bubbles. Month. Not. Roy. Astron. Soc., v. 355, p. 995-1004, 2004.

GONÇALVES, F. A. G. Produção de lipase extracelular por leveduras em cultivo submerso. Belo Horizonte, Dissertação de Mestrado. Departamento de Ciências de Alimentos da Universidade Federal de Minas Gerais. 2007

LUCAS, E. F.; SOARES, B. G.; MONTEIRO, E. E. C., Caracterização de Polímeros, Determinação de peso molecular e análise térmica. E-papers. Rio de Janeiro, 2001.

MARTINS, A. B. Comparação entre agitação mecânica e ultrassônica na Síntese de ésteres de aromas catalisada por lipase. Trabalhos de Conclusão de Curso de Graduação da Universidade Federal do Rio Grande do Sul, Porto Alegre, 2012.

MARTINS, A. B.; DA SILVA, A. M.; SCHEIN, M. F.; GARCIA-GALAN, C.; ZÁCHIA AYUB, M. A.; FERNANDEZ-LAFUENTE, R.; RODRIGUES, R. C. Comparison of the performance of commercial immobilized lipases in the synthesis of different flavor esters. J. Mol. Catal. B: Enzym., v. 105, p. 18-25, 2014.

OZYILMAZ, G.; GEZER, E. Production of aroma esters by immobilized Candida rugosa and porcine pancreatic lipase into calcium alginate gel. J. Mol. Catal. B: Enzym., v. 64, p. $140-145,2010$.

PAROUL, N.; BIASI, A.; ROVANI, A. C.; PRIGOL, C.; DALLAGO, R.; TREICHEL, H.; OLIVEIRA, D. Enzymatic production of linalool esters in organic and solvent-free system. Bioprocess Biosyst. Eng., v. 33, p. 583-589, 2010.

PAROUL, N.; GRZEGOZESKI, L. P.; CHIARADIA, V.; TREICHEL, H.; CANSIAN, R. L.; OLIVEIRA, J. V.; OLIVEIRA, D. Solvent-free geranyloleate production by enzymatic esterificarion. Bioprocess Biosyst. Eng., v. 34, p. 323-329, 2011.

PIRES-CABRAL, P.; FONSECA, M. M. R.; FERREIRA-DIAS, S. Modelling the production of ethyl butyrate catalysed by Candida rugosa lipase immobilized in polyurethane foams. Chem. Biochem. Eng., v. 33, p. 148-158, 2007.

SANTOS, R. D. Produção Enzimática de Poli (E-Caprolactona) em Dióxido de Carbono Supercrítico. Universidade Federal de Santa Catarina, Centro Tecnológico, Programa de Pós-Graduação em Engenharia de Alimentos, Florianópolis/SC, 2011.

VALDEZ-PEÑA, A. U.; ESPINOZA-PEÑA, J. D.; BALAGURUSAMY, N.; SANDOVALFABIAN, G. C.; HERNANDEZ-RIBERA, A.; DE-LA-GARZA-RODRIGUEZ, N. D.; CONTRERAS-ESQUIVEL, J. C. Screening of industrial enzymes for deproteinization of shrimp head for chitin recovery. Food Sci. Technol. v. 19, p. 553-557, 2010. 